\title{
Novel Approach for Characterizing pH-Dependent Uptake of lonizable Chemicals in Aquatic Organisms
}

\author{
Maja V. Karlsson, ${ }^{\dagger}$ Laura J. Carter, ${ }^{\dagger}{ }^{\circledR}$ Annika Agatz, ${ }^{\dagger}$ and Alistair B.A. Boxall* ${ }^{\dagger}$ (৫) \\ ${ }^{\dagger}$ Environment Department, University of York, Heslington, York YO10 5NG, U.K.
}

Supporting Information

\begin{abstract}
Here, we present and evaluate a combined experimental and modeling approach for characterizing the uptake of ionizable chemicals from water and sediments into aquatic organisms under different $\mathrm{pH}$ conditions. We illustrate and evaluate the approach for two pharmaceuticals (diclofenac and fluoxetine) and one personal care product ingredient (triclosan) for the oligochaete Lumbriculus variegatus. Initially, experimental data on the uptake of the three chemicals at two $\mathrm{pH}$ values were fitted using a toxicokinetic model to derive uptake and depuration constants for the neutral and ionized species of each molecule. The derived constants were then used to predict uptake from water and sediment for other $\mathrm{pH}$ conditions. Evaluation of predictions against corresponding experimental data showed good predictions of uptake for all test chemicals from water for different $\mathrm{pH}$ conditions and reasonable predictions of uptake of fluoxetine and diclofenac from a sediment. Predictions demonstrated that the level of uptake of the study chemicals, across $\mathrm{pH}$ ranges in European streams, could differ by up to a factor of 3035. Overall, the approach could be extremely useful for assessing internal exposure of aquatic organisms across landscapes with differing $\mathrm{pH}$. This could help support better characterization of the risks of ionizable chemicals in the aquatic environment.
\end{abstract}

\section{INTRODUCTION}

A wide range of pharmaceuticals and ingredients used in personal care products has been detected in natural environments across the globe. ${ }^{1-5}$ The presence of these chemicals in the environment has prompted concerns over potential toxic effects in nontarget organisms. For a chemical to elicit an effect in an organism, it must usually be first taken up from the ambient environment. Understanding the internal exposure of a chemical can provide valuable insights to inform our understanding of the effects of chemicals in organisms. The information can also help in extrapolating from effects in standard laboratory studies to effects across different exposure scenarios. ${ }^{6,7}$ For example, for active pharmaceutical ingredients (APIs), it has been suggested that by understanding the internal concentrations in organisms in the natural environment and the presence/absence of the target receptors and pathways for the API, it may be possible to predict potential ecological effects of pharmaceuticals based on preclinical and clinical pharmacological data that are produced in the drug development process. $^{8}$

It has been estimated that between 85 and $95 \%$ of APIs are ionizable ${ }^{9}$ and therefore there is the potential that the behavior of these chemicals in the environment may be affected by changes in $\mathrm{pH}$. As the $\mathrm{pH}$ of natural water bodies range from 2.2 to $9.8,{ }^{10,11}$ the fate and effects of APIs could vary significantly across broad landscapes. A number of studies have explored the effects of $\mathrm{pH}$ on the uptake and toxicity of ionizable APIs from/in water. ${ }^{12,13}$ Nakamura et al. ${ }^{12}$ investigated the toxicity and bioconcentration of fluoxetine, a weak base, in Japanese medaka (Oryzias latipes) at $\mathrm{pH}$ values of 7, 8, and 9. Median lethal concentrations ranged from $0.2 \mathrm{mg} / \mathrm{L}$ at $\mathrm{pH} 9$ to $5.5 \mathrm{mg} / \mathrm{L}$ at $\mathrm{pH}$ 7. The toxicological observations were explained by differences in bioconcentration factors (BCF) at different $\mathrm{pH}$ values which ranged from 13 at $\mathrm{pH} 7$ to 330 at $\mathrm{pH}$ 9.

Modeling approaches have been proposed to estimate the effects of environmental $\mathrm{pH}$ on accumulation ${ }^{14-16}$ and effects ${ }^{17}$ of ionizable chemicals, including APIs, in organisms. For example, Meredith-Williams et al. ${ }^{14}$ suggested that the uptake of APIs into invertebrates (Gammarus pulex and Notonecta glauca) could be predicted based on a chemicals $\mathrm{pH}$-corrected liposome-water partition coefficient $\left(\log D_{\text {lip-water }}\right)$. Nichols et al. ${ }^{15}$ modeled the uptake of the weak base diphenhydramine into fish plasma using a model that accounts for acidification at the gill surface. The model assumed that the undissociated form of the molecule diffuses freely across the branchial epithelium. The membrane transport of the cation is estimated in relation to the neutral form using a term varying from 0 to 1 . Fu et al. ${ }^{16}$ proposed regression equations that estimate bioconcentration

Received: March 9, 2017

Revised: $\quad$ May 24, 2017

Accepted: May 29, 2017

Published: May 29, 2017 
factors of acids and bases based on the octanol-water partition coefficient $\left(K_{\mathrm{ow}}\right)$ and the logarithmic acid dissociation constant $\left(\mathrm{p} K_{\mathrm{a}}\right)$ of a molecule.

These previous studies have focused on the situation where the external and internal concentrations of the ionizable chemical are in equilibrium and have typically taken an overly simplistic approach to dealing with the ionized form of the molecules. By using a more mechanistic approach that considers the rate of uptake of the ionized and neutral species of a molecule, it may be possible to better estimate the internal exposure of an organism over time for varying $\mathrm{pH}$ conditions typically found in the natural environment. This could be invaluable for assessing the degree of risk of these chemicals.

Here, we present a new combined experimental and modeling approach for characterizing the uptake of ionizable chemicals, such as APIs, in aquatic invertebrates over time for different $\mathrm{pH}$ conditions. A schematic of the model underlying the approach is shown in Figure 1. The approach characterizes

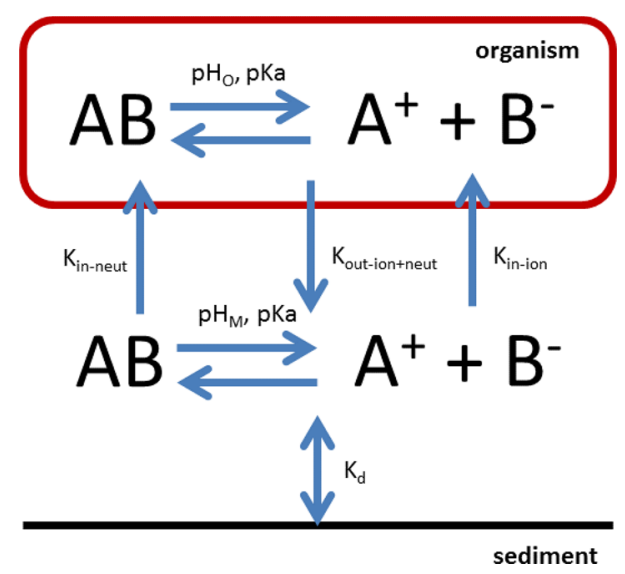

Figure 1. Schematic diagram of the modeling approach for estimating uptake of an ionizable chemical, $\mathrm{AB}$, into an aquatic invertebrate. $K_{\text {in-neut }}=$ uptake rate constant for the neutral species; $K_{\text {in-ion }}=$ uptake rate constant for the ionized species; $K_{\text {out }}=$ elimination rate constant for the combination of the neutral and ionised species; $\mathrm{pH}_{\mathrm{M}}=\mathrm{pH}$ of the external media; $\mathrm{pH}_{\mathrm{O}}=$ internal $\mathrm{pH}$ of the organism.

the uptake of an ionizable chemical into an organism over time based on the fraction of the ionized and nonionized species of a molecule in water for the $\mathrm{pH}$ of interest and uptake rate constants for the neutral and ionized form of the molecule which are derived from experimental uptake studies performed at two $\mathrm{pH}$ values. It is assumed that the internal $\mathrm{pH}$ of the organism is constant, and unaffected by the external $\mathrm{pH}$, so a constant depuration rate constant for the ion and neutral form is used. If the invertebrate is a sediment-dwelling organism then uptake can be characterized based on the concentration of the ionizable chemical in the pore water, which is derived from the concentration of the compound in the sediment and the sediment sorption coefficient $\left(K_{d}\right)$. This is based on the assumption that uptake is occurring only from the pore water. We illustrate and evaluate the approach for two ionizable APIs and one ionizable personal care product ingredient and the oligochaete Lumbriculus variegatus for water-only exposures at a range of $\mathrm{pH}$ values and using previously published data on uptake of the chemicals from one sediment type.

\section{MATERIALS AND METHODS}

Underlying Model. The kinetic model used is based on a first-order one-compartment toxicokinetic model that is used to describe the internal concentrations within an organism over time $\left(\mathrm{d} C_{\text {int }} / \mathrm{d} t\right)$ (mass/volume) based on exposure medium concentrations and uptake and depuration rates (eq 1). Here, we extend this toxicokinetic model to account for differences in uptake of the neutral and ionized forms over time (eq 2).

$$
\begin{aligned}
\mathrm{d} C_{\text {int }} / \mathrm{d} t= & k_{\text {in }} \times C_{\mathrm{w}}-k_{\text {out }} \times C_{\text {int }} \\
\mathrm{d} C_{\text {int }} / \mathrm{d} t= & \left(k_{\text {in-ion }} \times\left(f_{\text {ion }} \times C_{\mathrm{w}}\right)+k_{\text {in-neut }}\right. \\
& \left.\times\left(f_{\text {neut }} \times C_{\mathrm{w}}\right)\right)-k_{\text {out }} \times C_{\text {int }}
\end{aligned}
$$

where $C_{\mathrm{w}}(\mathrm{mol} / \mathrm{mL})$ is the concentration of the ionizable chemical in the water; $C_{\text {int }}(\mathrm{mol} / \mathrm{g})$ is the concentration of the chemical in the organism; $k_{\text {in-ion }}\left(\mathrm{L} \mathrm{kg}^{-1} \mathrm{~d}^{-1}\right)$ is the uptake rate constant of the ionic species of the chemical; $k_{\text {in-neut }}\left(\mathrm{L} \mathrm{kg}^{-1}\right.$ $\mathrm{d}^{-1}$ ) is the uptake rate constant for the neutral form of the chemical; $f_{\text {ion }}(-)$ is the fraction of the chemical in the ionized form at the test $\mathrm{pH} ; f_{\text {neut }}(-)$ is the fraction of the neutral form of the chemical at the test $\mathrm{pH}$; and $k_{\text {out }}\left(\mathrm{L} \mathrm{kg}^{-1} \mathrm{~d}^{-1}\right)$ is the depuration rate constant. The depuration rate constant is not altered in comparison to the original model because the $\mathrm{pH}$ within the organism is assumed to be independent of the external $\mathrm{pH}$ and thus fractioning of the chemical into the ionized and neutral form is constant within the organism, and the depuration rate constant is independent of $\mathrm{pH}$ alterations once derived. This assumption had to be made because, to our knowledge, no information is available on the internal $\mathrm{pH}$ of $L$. variegatus and the circumstances on if, when and to what extent this $\mathrm{pH}$ changes over the life span or is independent of external $\mathrm{pH}$.

The uptake and depuration rates needed to parameterize the model are obtained from uptake and depuration experiments on the organism of interest. The tests need to be performed at a minimum of two $\mathrm{pH}$ values within the naturally occurring environmental $\mathrm{pH}$ ranges. One of the $\mathrm{pH}$ values needs to be chosen so that the test chemical is either fully or not ionized to allow the parameterization of $k_{\text {in ion }}$ and $k_{\text {in neut }}$ in a two-point calibration. The Henderson-Hasselbach Equation is used to estimate the fraction of dissociation of the study chemicals at each of the test $\mathrm{pH}$ values. By fitting eq 2 to experimental data for both $\mathrm{pH}$ conditions, $k_{\text {in neut }}, k_{\text {in ion }}$ and $k_{\text {out }}$ can be derived. These rate constants can then be used, in conjunction with ionization predictions from the Henderson-Hasselbach Equation, in the toxicokinetic equation to predict uptake from water for other $\mathrm{pH}$ conditions.

If the organism of interest is a sediment-dwelling organism then concentrations in the organism can also be estimated according to concentrations in pore water of a known $\mathrm{pH}$ based on the sediment-water distribution coefficient $K_{\mathrm{d}}(\mathrm{L} / \mathrm{kg})$ of the chemical for the sediment of interest which can be obtained from batch sorption studies based on the OECD 106 Batch Equilibrium Method. ${ }^{18}$ Concentrations of test chemicals in sediment over time are used, alongside the sorption coefficient, to estimate concentrations in the sediment pore water over time using eq 3.

$$
C_{\mathrm{pw}}=C_{\mathrm{sed}} /\left(\left(K_{\mathrm{d}} \times(\% \text { sed } / \% \text { water }) \times \text { bulk density }\right)+1\right)
$$


where $C_{\mathrm{pw}}$ and $C_{\text {sed }}$ are the concentrations of the chemical in pore water $(\mathrm{mol} / \mathrm{mL})$ and sediment $(\mathrm{mol} / \mathrm{g} \mathrm{wwt})$, respectively, and $\%$ sed and $\%$ water are calculated based on the moisture content of the sediment.

Illustration and Evaluation of the Approach for Diclofenac, Fluoxetine, and Triclosan. To illustrate and test the approach, we performed studies into the uptake and depuration of diclofenac (a nonsteroidal anti-inflammatory compound), fluoxetine (an antidepressant), and triclosan (an antimicrobial compound). Studies were done using water at four $\mathrm{pH}$ values: two of these being used to derive uptake and depuration constants for the neutral and ionic species of each molecule and two being used to test the predictive power of the approach for other test conditions. A previous data set on uptake of the study chemicals from sediment was used to evaluate whether the method can be extended to predict uptake from the sediment compartment.

Test Chemicals. Experimental studies were done using ${ }^{14} \mathrm{C}$ labeled versions of the test chemicals, ranging in specific activity from 2.04 to $2.43 \mathrm{GBq} \mathrm{mmol}^{-1}$. Diclofenac was obtained from PerkinElmer (Boston, MA, USA), fluoxetine was obtained from American Radiolabeled Chemicals (St. Louis, MO, USA), and triclosan was obtained from Unilever (Colworth, UK).

Test Organism. Animals were initially reared in 20-L glass aquaria containing artificial pond water (APW, Naylor et al. 1989), at $20 \pm 2{ }^{\circ} \mathrm{C}$, using a 16:8 h light/dark cycle. Shredded unbleached tissue paper was used as a substrate and the culture water was renewed once a week. The cultures were fed with ground fish food (Tetramin, Tetra Werke, Melle, Germany) twice a week.

Uptake and Depuration Studies. Uptake and depuration rates of the study chemicals into and from $L$. variegatus were determined in artificial pond water (APW) and soft standard reference water (SRW) adjusted to either $\mathrm{pH} 5.5,7$, or 8.5 based on an approach recommended by the USEPA. ${ }^{19}$ The $\mathrm{pH}$ was not buffered or manipulated in the APW ( $\mathrm{pH} 7.4$ ) treatment. For the SRW treatments, $\mathrm{NaH}_{2} \mathrm{PO}_{4}$ was used and the $\mathrm{pH}$ was maintained for the duration of the uptake and depuration phase through the addition of either $0.1 \mathrm{M} \mathrm{HCl}$ or $\mathrm{NaOH}$.

Prior to the studies, the L. variegatus were acclimatized to the test conditions for $18 \mathrm{~h}$. For the uptake studies, animals were then exposed in groups of 10 , contained in $40 \mathrm{~mL}$ of either APW or the SRW at the different $\mathrm{pH}$ values, to between 3-12 nmol L ${ }^{-1}$ of test chemical for $3,6,12,24$, or $48 \mathrm{~h}$. All test concentrations were below toxicological thresholds. For the depuration studies, groups of animals were exposed to the test chemical for $48 \mathrm{~h}$ after which time they were transferred to either APW or pH-adjusted SRW for 3, 6, 12, 24, or $48 \mathrm{~h}$. Three replicates per time point and $\mathrm{pH}$ treatment were used. The study temperature was $20 \pm 2{ }^{\circ} \mathrm{C}$ and the beakers were kept in the dark throughout the test to minimize potential photodegradation of the test chemical. Control beakers containing SRW and radio-labeled test chemical were used to monitor sorption to the jars. At the end of the exposure, samples of the test media were taken for chemical analysis. Exposed worms were rinsed with distilled water, blotted dry on tissue paper, weighed, and then analyzed.

Chemical Analysis. Concentrations of the study chemicals in test media and worm extracts were determined by Liquid Scintillation Counting (LSC) using a Beckman LS 6500 LSC counter (Beckman Coulter Inc., Fullerton, CA, USA). For the analysis of test media, $1 \mathrm{~mL}$ of sample was taken and placed into a $20-\mathrm{mL}$ scintillation vial and $10 \mathrm{~mL}$ of Ecoscint $\mathrm{A}$ scintillation cocktail (National Diagnostics) was added. For the analysis of worm samples, animals were placed in $20-\mathrm{mL}$ scintillation vials, $2 \mathrm{~mL}$ of tissue solubilizer (Soluene-350, PerkinElmer, Waltham, MA, USA) was then added, and the vials were left for $24 \mathrm{~h}$ to allow the worm tissue to dissolve completely. Prior to scintillation counting, $10 \mathrm{~mL}$ of Hionic Fluor scintillation cocktail (PerkinElmer) was added to the vials.

Samples were counted three times for $5 \mathrm{~min}$. Counts were corrected for background activity by using blank controls. Counting efficiency and color quenching were corrected using the external standard ratio method. A mass balance was performed to account for all radioactivities present in the experiments by summing the mass of chemical contained in the organism and in the test media for each treatment and time point.

Parameterization and Testing of the Model against Experimental Data. For the water-only studies, for each chemical tested, there was one experiment that was conducted at a $\mathrm{pH}$ where the molecule was almost fully dissociated (diclofenac, $\mathrm{pH}$ 8.5; fluoxetine, $\mathrm{pH}$ 5.5) or nondissociated (triclosan, $\mathrm{pH}$ 5.5). These experiments were used to fit the depuration rate constant and the uptake rate constant $\left(k_{\text {in-ion }}\right.$ for diclofenac and fluoxetine and $k_{\text {in-neut }}$ for triclosan) for the chemical to measured internal concentrations by fixing the fraction of ionization to either 0 or 1 . The experiment with the most deviating $\mathrm{pH}$ (i.e., the highest variation in the fractioning of ionization) was then used to fit the second uptake rate constant keeping the prior fitted uptake rate constant and the depuration rate constant fixed and adjusting the fraction of ionization and neutralization. Measured $\mathrm{pH}$ values were used in these calculations. Modeling was conducted in OpenModel V 2.4.2. (http://openmodel.info/) using the Runge-Kulta $\left(4^{\text {th }}\right.$ Order) ordinary differential equation method (with Monte Carlo simulations to obtain the $95 \%$ confidence interval and the Nash-Sutcliffe Efficiency calculation for goodness of fit indication where a value $\geq 0$ shows an acceptable fit/prediction and a value $<0$ indicates an unacceptable fit) using the full data set and also using the minimized design method described in Carter et al. ${ }^{20}$

These fitted rate constants and the fractions of ionization, derived from the $\mathrm{pH}$ measurements, in the other two experiments were then used to predict the internal concentration over time in the uptake studies performed at the other $\mathrm{pH}$ values of 7.0 (SRW) and 7.4 (APW) using both the full and minimized methods.

To evaluate the approach for chemical uptake from sediment, we used data from a previously reported study into the uptake and depuration of diclofenac, fluoxetine, and triclosan into $L$. variegatus from a sediment obtained from Buttercrambe in Yorkshire $^{21}$ (see Supporting Information (SI) Section 1 for more details). The $\mathrm{pH}$ of the sediment was 7.67 and the bulk density of the test sediment was estimated to be $1.16 \mathrm{~g} / \mathrm{mL}$ using the approach proposed by Avnimelech et al. ${ }^{22}$ The sorption coefficients between water and the sediment was obtained using a batch sorption test and were found to be 4.2, 422.5, and 241.2 for diclofenac, fluoxetine, and triclosan, respectively. A full description of the methods used to calculate the sediment sorption coefficients is provided in SI Section 2. The sorption data were used to estimate concentrations of the study chemicals in pore water over the duration of the study (eq 3) and internal concentrations in the organisms were then 

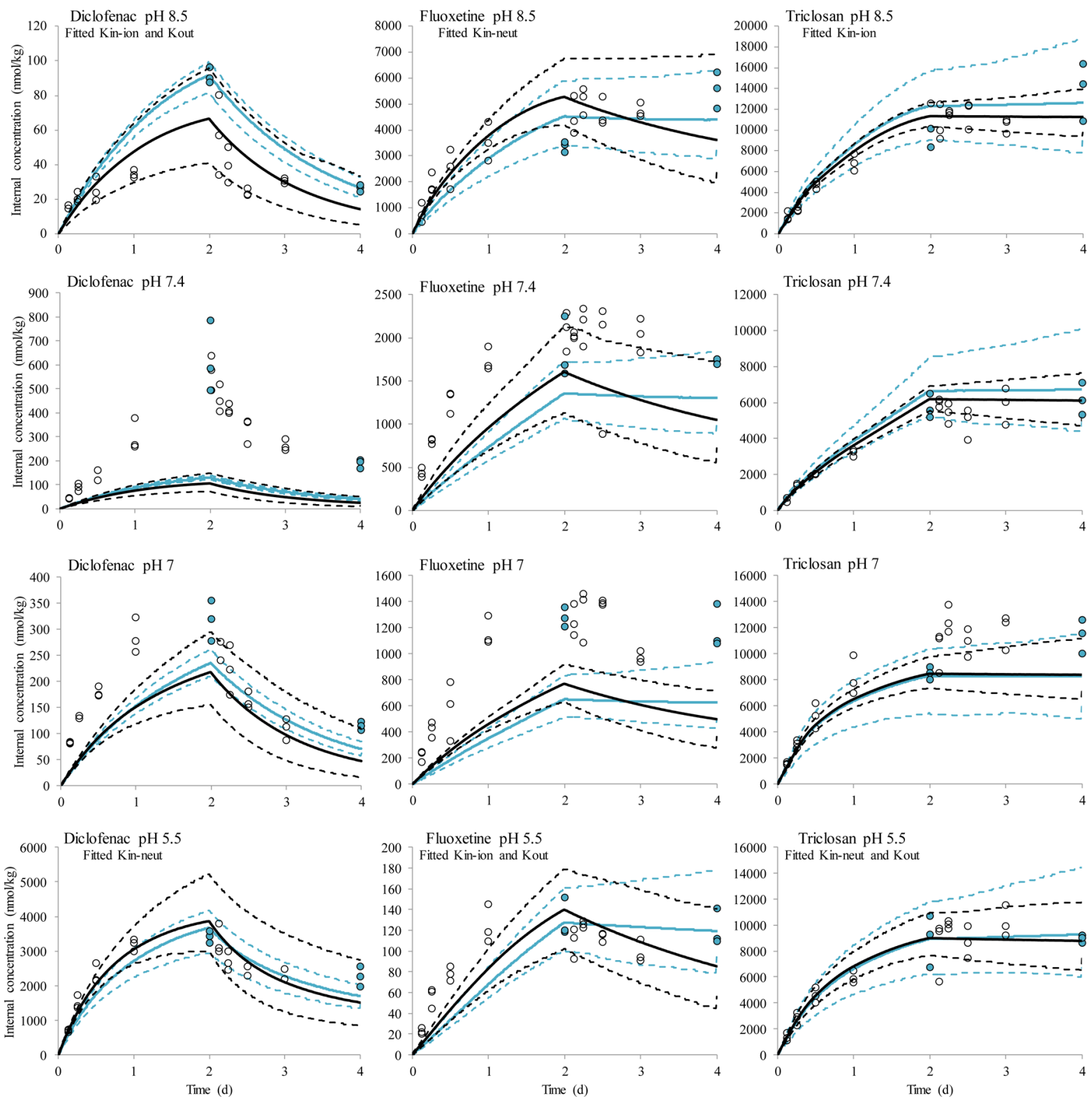

Figure 2. Measured (points) and simulated (lines) internal concentration of three ionizable chemicals in Lumbriculus variegatus in water at different $\mathrm{pH}$ values. Dashed lines indicate the $95 \%$ confidence interval of the simulations following the parameter estimation with the full data set (black) or according to the minimized design method (blue).

estimated from the pore water concentration using the same approach as used in the water-only studies (eq 2). Experimental observations were then compared to the predictions.

\section{RESULTS AND DISCUSSION}

Uptake and Depuration Experiments in Lumbriculus variegatus. The $\mathrm{pH}$ in the APW treatments ranged from 7.5 to 8.3. For the SRW, the $\mathrm{pH}$ of the $\mathrm{pH} 5.5$ and 7 treatments remained within $\pm 0.3 \mathrm{pH}$ units of the nominal value. For the $\mathrm{pH} 8.5$ treatment, measured $\mathrm{pH}$ decreased by up to $1.1 \mathrm{pH}$ unit during the experiment. Radioactivity in the media in the chemical controls, containing test chemical and aqueous media only, was stable for the duration of the study indicating that there was no sorption to the vessels. Losses of activity from the water phase in the beakers with organisms could be explained by uptake into the study organisms. Mass balance calculations showed recoveries of greater than $89 \%$ of the applied radioactivity in the different treatments (SI, Section 3 Table S1). No mortality was observed either in the treatments or in the controls during the uptake or depuration phase.

The uptake and depuration studies at different $\mathrm{pH}$ values demonstrate the importance of exposure medium $\mathrm{pH}$ for predicting ionizable chemical uptake into nontarget organisms. At the end of the 48-h uptake phase 47- and 37-fold differences were seen between the internal concentrations in L. variegatus in the highest and lowest $\mathrm{pH}$ treatments for diclofenac and fluoxetine, respectively, whereas the fraction of ionization only changed by 3 and $2 \%$, respectively. These experimental results demonstrate that the uptake of ionizable chemicals can, in certain circumstances, be extremely sensitive to changes in exposure medium $\mathrm{pH}$ where the $\mathrm{p} K_{\mathrm{a}}$ value of a chemical falls within the environmentally relevant $\mathrm{pH}$ range of $2.2-9.8 .^{10}$ The hydrophobicity and value of the chemical $\mathrm{p} K_{\mathrm{a}}$ in relation to environmental $\mathrm{pH}$ ranges is important-for diclofenac which is 
an acid with a $\mathrm{pK}_{\mathrm{a}}$ toward the lower end of typical environmental $\mathrm{pH}$, large differences in uptake and toxicity might be expected across environmental $\mathrm{pH}$ values, whereas for triclosan, which is a hydrophobic acid with a $\mathrm{p} K_{\mathrm{a}}$ toward the upper end of the environmental $\mathrm{pH}$ range, lower variability in uptake might be expected as the chemical will not be as extensively ionized and the neutral form would be the dominant species.

Evaluation of the Modeling Approach. The first-order one-compartment model was successfully fitted (success being indicated by Nash-Sutcliffe Efficiency values well above 0 (SI Section 4 Table S2) to the uptake and depuration measurements for the diclofenac, fluoxetine, and triclosan treatments for $\mathrm{pH} 5.5$ and 8.5 (Figure 2). Resulting uptake parameters for the neutral and ionized species and the combined depuration rates of the chemicals, obtained using both the full and minimized methods, are provided in Table 1. For diclofenac

Table 1. Physicochemical Properties of the Compounds Tested, Range of Measured pH Values during Each Study, and Derived Uptake and Depuration Rate Constants (Standard Deviations Are Shown in Parentheses)

\begin{tabular}{|c|c|c|c|}
\hline & diclofenac & fluoxetine & triclosan \\
\hline $\log K_{\mathrm{ow}}$ & 4.06 & 4.09 & 5.17 \\
\hline $\mathrm{p} K_{\mathrm{a}}$ & 4.01 & 9.62 & 7.90 \\
\hline acid/base & acid & base & acid \\
\hline \multicolumn{4}{|c|}{ measured $\mathrm{pH}$} \\
\hline water $\mathrm{pH} 5.5$ & $5.5-5.7$ & $5.4-5.6$ & $5.4-5.6$ \\
\hline water $\mathrm{pH} 7.0$ & $7.0-7.2$ & $6.8-7.9$ & $7.0-7.2$ \\
\hline water $\mathrm{pH} 7.4$ & $7.6-8.3$ & $7.5-7.6$ & $7.9-8.3$ \\
\hline water $\mathrm{pH} 8.5$ & $7.4-8.9$ & $7.7-8.7$ & $7.7-8.6$ \\
\hline sediment & 7.67 & 7.67 & 7.67 \\
\hline \multicolumn{4}{|c|}{$f_{\text {ion }}$ used for modeling } \\
\hline water $\mathrm{pH} 5.5$ & $0.9731(0.0043)$ & $1(0.0004)$ & $0(0.0004)$ \\
\hline water $\mathrm{pH} 7.0$ & $0.9993(0.0001)$ & $0.9959(0.0053)$ & $0.1445(0.0146)$ \\
\hline water $\mathrm{pH} 7.4$ & $0.9998(0.0001)$ & $0.9915(0.0014)$ & $0.6076(0.1522)$ \\
\hline water $\mathrm{pH} 8.5$ & $1(0.0001)$ & $0.9458(0.0278)$ & $0.7213(0.1055)$ \\
\hline $\begin{array}{l}\text { sediment } \mathrm{pH} \\
7.64\end{array}$ & $0.9999(0.001)$ & $0.9889(0.001)$ & $0.3706(0.001)$ \\
\hline \multicolumn{4}{|c|}{ full data set } \\
\hline$K_{\text {in-neut }}\left(\mathrm{L} \mathrm{kg}^{-1}\right)$ & $17811(585)$ & $14203(747)$ & $1119(76.4)$ \\
\hline $\begin{array}{c}K_{\text {in-ion }} \\
\left.\mathrm{d}^{-1}\right)\end{array}\left(\mathrm{L} \mathrm{kg}^{-1}\right.$ & $5.75(0.97)$ & $11.43(1.42)$ & $1181(50.9)$ \\
\hline$\underset{\left.\mathrm{d}^{-1}\right)}{K_{\text {out }}\left(\mathrm{L} \mathrm{kg}^{-1}\right.}$ & $0.86(0.18)$ & $0.25(0.09)$ & $0.01(0.035)$ \\
\hline \multicolumn{4}{|c|}{ minimized design } \\
\hline$\underset{\substack{\left.\text { in-neut } \\
\mathrm{d}^{-1}\right)}}{ }\left(\mathrm{L} \mathrm{kg}^{-1}\right.$ & $14342(1007)$ & $9735(1130)$ & $1084(162)$ \\
\hline$K_{\text {in-ion }}\left(\mathrm{L} \mathrm{kg}^{-1}\right)$ & $6.82(0.27)$ & $8.54(0.99)$ & $1302(156)$ \\
\hline $\begin{array}{c}K_{\text {out }}\left(\mathrm{L} \mathrm{kg} \mathrm{k}^{-1}\right. \\
\left.\mathrm{d}^{-1}\right)\end{array}$ & $0.634(0.04)$ & $0.039(0.06)$ & $0.00001(0.059)$ \\
\hline
\end{tabular}

and fluoxetine the uptake rate constants for the ionized form of the molecules were more than 3 orders of magnitude lower than the corresponding neutral form. Despite the fact that it is typically assumed that the uptake of the ionic form of a molecule is lower than the neutral form (as observed for diclofenac and fluoxetine), for triclosan, this was found not to be the case with the uptake rates for the neutral and ionized forms of the molecule being similar. The triclosan findings are similar to previous observations into the uptake of chlorinated phenols at fish gills where uptake at different $\mathrm{pH}$ values was similar even though the degree of ionization of the chlorinated phenols at the $\mathrm{pH}$ values studied was very different. ${ }^{23}$

The full and the minimized methods provided similar predictions demonstrating that the minimized approach can be used to derive uptake and depuration rate constants for the neutral and ionic species of a molecule and thus reduce the amount of experimental effort (by a factor of 4) needed in studies of this type. Predictions of concentrations in $L$. variegatus based on the derived $K_{\text {in-neut }}$ and $K_{\text {in-ion }}$ values to estimate uptake from water for the other $\mathrm{pH}$ conditions (i.e., $\mathrm{pH} 7$ and 7.4) are shown in Figure 2. Overall the model performed best for triclosan followed by fluoxetine and diclofenac. While predictions, using rate constants derived using both the full and minimized approaches, accurately matched observations for triclosan (Nash-Sutcliffe Efficiency $>0.56$ ) the model significantly underestimated internal concentrations of fluoxetine and diclofenac at pH 7.4 (NashSutcliffe Efficiency <0) and fluoxetine at $\mathrm{pH} 7.0$ when rate constants using the full approach were used, and significantly underestimated internal concentrations of diclofenac and fluoxetine at $\mathrm{pH} 7.4$ when rate constants obtained using the minimized approach were used. Even so, predicted internal concentrations of fluoxetine, obtained using the model, were within a factor of 2 of experimental values while internal concentration predictions for diclofenac were within a factor of 4 of experimental values. Given the large observed range seen in the uptake experiments for fluoxetine (a 37-fold difference between $\mathrm{pH} 5.5$ and $\mathrm{pH}$ 8.50) and diclofenac (a 47-fold difference between $\mathrm{pH} 5.5$ and 8.5), the model predictions seem reasonable and useful for use in spatial environmental risk assessments.

Comparison of the model predictions of internal concentrations of the chemicals for the sediment studies with measured concentrations in L. variegatus (Figure 3) showed that the approach worked reasonably well for diclofenac and fluoxetine with predictions being less than a factor of 5 lower than empirical observations. For triclosan, however, predicted concentrations in the worms were 10-15 times lower than the experimental observations. The mismatch for all three chemicals might be explained by differences between the physicochemical characteristics of the sediment pore water and the media used in the water-only studies. Previous studies with neutral organic chemicals have shown that dissolved organic carbon, which will be present in the sediment water, can enhance the diffusive mass transfer of compounds. ${ }^{24}$ It is also possible that the sorption coefficients used, which were obtained using OECD-type batch sorption studies using one concentration, do not reflect the actual sorption behavior of the chemical in the sediment-worm system. For example, sorption isotherms may deviate from linearity at high concentrations. Concentrations used in the sorption experiments were however low (15-22.6 nM) and within an order of magnitude of concentrations observed in the aqueous phase of the sediment uptake studies (diclofenac 21.5-23.5 nM; fluoxetine 5.30-5.82 $\mathrm{nM}$; and triclosan 1.64-3.5 nM). The differences for triclosan may also be partly explained by the fact that sediment ingestion has been shown to play a role in the uptake of this chemical by L. variegatus from this sediment ${ }^{21}$ while this has been shown to not be an important uptake route for diclofenac and fluoxetine. The impacts of pore water chemistry on both sorption and uptake and, for selected chemicals, ingestion, may therefore need to be considered in the future in order to develop approaches to better assess uptake from sediments across a 

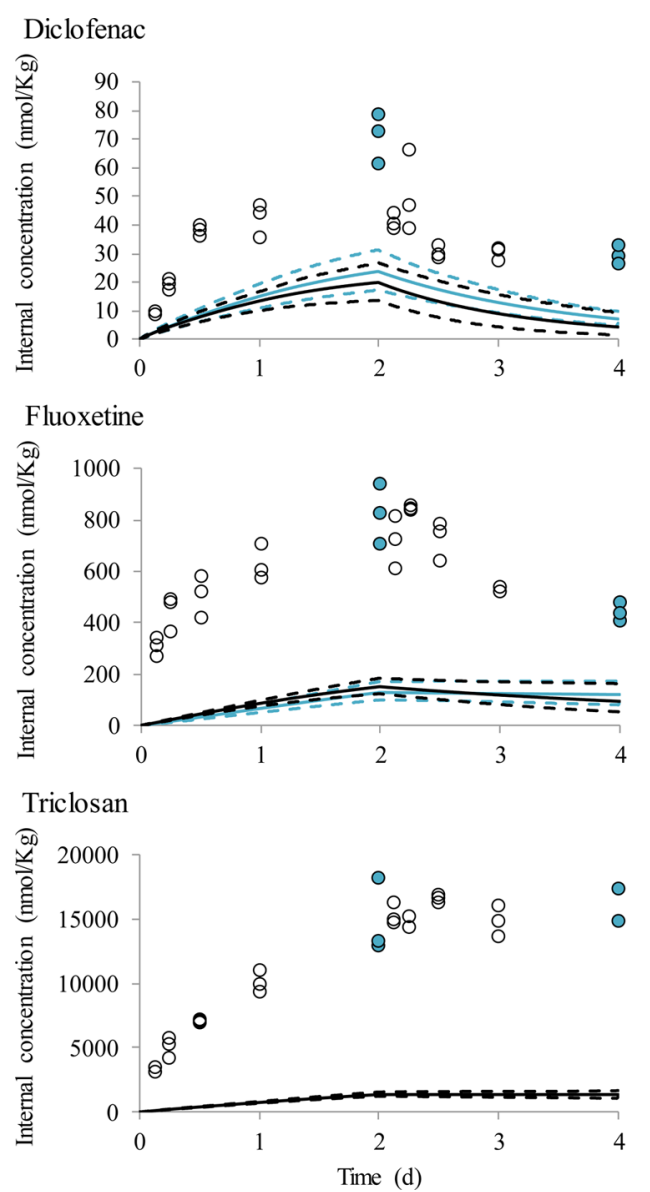

Figure 3. Comparison of measured (points) and predicted (lines) internal chemical concentrations over time in sediment-exposed Lumbriculus variegatus. Dashed lines indicate the $95 \%$ confidence interval of the simulations following the parameter estimation with the full data set (black) or according to the minimized design method (blue).

landscape. Finally, it is important to recognize that the studies presented here measured levels of radioactivity in the different components of the system over time. It is possible that, once accumulated, the study chemicals were metabolized to some degree. Differences in properties of the transformation products compared to the parent chemical may also contribute to the mismatch between predictions and experimental observations. Previous work we have performed into the uptake and metabolism of unlabeled compounds indicates that diclofenac is nonmetabolized by the worms while fluoxetine and triclosan may be metabolized to some degree. ${ }^{25}$

Implications for Environmental Risk Assessment. The application of the combined experimental and modeling approach to characterize internal concentrations worked reasonably well for all chemicals in the water-only studies and for diclofenac and fluoxetine in the sediment studies. The results indicate that, if data are available on exposure medium $\mathrm{pH}$ and concentrations in sediment for a landscape, by then deriving uptake and depuration rate constants for two $\mathrm{pH}$ conditions, it will be possible to establish the internal concentration of ionizable chemicals to within a factor of 4.0 in water- and sediment-dwelling invertebrates across the landscape over time. Further work on a wider variety of ionizable chemicals and sediments is, however, needed in order to test the general applicability of the approach. The generation of a more extensive data set on uptake and depuration constants of neutral and ionic species of molecules could, in the longer term, result in the development of models that allow prediction of uptake across a landscape based on chemical structure alone.

Incorporation of our approach into current risk assessment practices offers a move towards making risk assessment more representative of the natural environment. For example, in the $\mathrm{UK}$, typical streamwater $\mathrm{pH}$ ranges from 5.2 to 8.4. ${ }^{10}$ This increase of over $3 \mathrm{pH}$ units will result in changes in the ionized fraction of chemicals. For example, at $\mathrm{pH}$ 5.2, diclofenac will be 93.9\% ionized in comparison to complete ionization (100\%) at $\mathrm{pH}$ 8.4. On the basis of the relationship between uptake rates for ionized and neutral diclofenac presented in this study, if lumbricids occur in sediments across these $\mathrm{pH}$ ranges, the uptake of diclofenac in L. variegatus across UK streams could vary by up to a factor of 168 . For fluoxetine the differences in uptake would differ by up to a factor of 68 , whereas for triclosan only small differences in uptake might be expected across UK streams (factor 1.15). Taking into account the increased $\mathrm{pH}$ variation across European streams ( $\mathrm{pH}$ range of 2.2-9.8) these factors dramatically increase for diclofenac (3035) and fluoxetine (749), but stay almost constant for triclosan (1.20). Establishing which sites are of greatest concern based on $\mathrm{pH}$ data will allow for targeting monitoring and a more comprehensive evaluation of the risks. The combined experimental and modeling approach can be used to predict the internal concentration of ionizable chemicals across a wide spatial scale in water-sediment systems covering a broad range of $\mathrm{pH}$ values and sediment sorption coefficients.

Even with extensive monitoring data demonstrating the presence of ionizable chemicals in the aquatic environment, very little data currently exist with regard to measurements of these chemicals in biota, and even fewer studies have demonstrated the uptake of ionizable chemicals in watersediment systems. There is a real need to understand the uptake of ionizable chemicals in water and sediment systems to fully understand the risks these chemicals may pose to nontarget organisms. ${ }^{26}$ The model and experimental model parameterization approach presented in this paper offers a way to fill this knowledge gap by generating data on the internal concentration of selected ionizable chemicals in invertebrates such as $L$. variegatus and other aquatic species. The results clearly demonstrate that ionizable chemical uptake is sensitive to changes in exposure medium $\mathrm{pH}$ and this needs to be considered when evaluating the risk of such chemicals in aquatic systems. The modeling approach presented could be a very useful tool for assessing the risks of ionizable compounds to benthic organisms at the landscape scale in the future.

\section{ASSOCIATED CONTENT}

\section{S Supporting Information}

The Supporting Information is available free of charge on the ACS Publications website at DOI: 10.1021/acs.est.7b01265.

Detailed information on sorption of study compounds to sediment and mass balance calculations (PDF)

\section{AUTHOR INFORMATION}

\section{Corresponding Author}

*Phone: +44 1904 324791; e-mail: Alistair.boxall@york.ac.uk. ORCID

Laura J. Carter: 0000-0002-1146-7920 
Alistair B.A. Boxall: 0000-0003-3823-7516

\section{Notes}

The authors declare no competing financial interest.

\section{ACKNOWLEDGMENTS}

We thank Unilever who funded M.V.K.'s work on the project. L.J.C.'s contribution to the study received support from the EU/EFPiA Innovative Medicines Initiative Joint Undertaking (iPiE Grant 115735). A.A.'s contribution to the study received support from the Innovate UK-funded VFETL project. We also thank two anonymous reviewers for very useful insights on an earlier version of this manuscript.

\section{REFERENCES}

(1) Kolpin, D. W.; Furlong, E. T.; Meyer, M. T.; Thurman, E. M.; Zaugg, S. D.; Barber, L. B.; Buxton, H. T. Pharmaceuticals, hormones, and other organic wastewater contaminants in US streams, 19992000: A national reconnaissance. Environ. Sci. Technol. 2002, 36 (6), $1202-1211$.

(2) Lindqvist, N.; Tuhkanen, T.; Kronberg, L. Occurrence of acidic pharmaceuticals in raw and treated sewages and in receiving waters. Water Res. 2005, 39 (11), 2219-2228.

(3) Buser, H. R.; Poiger, T.; Muller, M. D. Occurrence and environmental behavior of the chiral pharmaceutical drug ibuprofen in surface waters and in wastewater. Environ. Sci. Technol. 1999, 33 (15), $2529-2535$.

(4) Kim, S. C.; Carlson, K. Temporal and spatial trends in the occurrence of human and veterinary antibiotics in aqueous and river sediment matrices. Environ. Sci. Technol. 2007, 41 (1), 50-57.

(5) Jelic, A.; Petrovic, M.; Barcelo, D. Multi-residue method for trace level determination of pharmaceuticals in solid samples using pressurized liquid extraction followed by liquid chromatography/ quadrupole-linear ion trap mass spectrometry. Talanta 2009, 80 (1), 363-371.

(6) van Wezef, A. P.; Devries, D. A. M.; Kostense, S.; Sijm, D.; Opperhuizen, A. Intraspecies variation in lethal body burdens of narcotic compounds. Aquat. Toxicol. 1995, 33 (3-4), 325-342.

(7) Escher, B. I.; Hermens, J. L. M. Internal exposure: Linking bioavailability to effects. Environ. Sci. Technol. 2004, 38 (23), 455A$462 \mathrm{~A}$.

(8) Huggett, D. B.; Cook, J. C.; Ericson, J. F.; Williams, R. T. A theoretical model for utilizing mammalian pharmacology and safety data to prioritize potential impacts of human pharmaceuticals to fish. Hum. Ecol. Risk Assess. 2003, 9 (7), 1789-1799.

(9) Manallack, D. T. The acid-base profile of a contemporary set of drugs: implications for drug discovery. Sar and Qsar in Environmental Research 2009, 20 (7-8), 611-655.

(10) British Geological Survey. $p H$ in stream waters: Great Britain; GBASE Geochemical Map.; Keyworth, Nottingham, UK, 2009.

(11) Bundschuh, M.; Weyers, A.; Ebeling, M.; Elsaesser, D.; Schulz, R. Narrow pH Range of Surface Water Bodies Receiving Pesticide Input in Europe. Bull. Environ. Contam. Toxicol. 2016, 96 (1), 3-8.

(12) Nakamura, Y.; Yamamoto, H.; Sekizawa, J.; Kondo, T.; Hirai, N.; Tatarazako, N. The effects of $\mathrm{pH}$ on fluoxetine in Japanese medaka (Oryzias latipes): Acute toxicity in fish larvae and bioaccumulation in juvenile fish. Chemosphere 2008, 70 (5), 865-873.

(13) Valenti, T. W., Jr.; Perez-Hurtado, P.; Chambliss, C. K.; Brooks, B. W. Aquatic toxicity of sertraline to pimephales promelas at environmentally relevant surface water $\mathrm{pH}$. Environ. Toxicol. Chem. 2009, 28 (12), 2685-2694.

(14) Meredith-Williams, M.; Carter, L. J.; Fussell, R.; Raffaelli, D.; Ashauer, R; Boxall, A. B. A. Uptake and depuration of pharmaceuticals in aquatic invertebrates. Environ. Pollut. 2012, 165, 250-258.

(15) Nichols, J. W.; Du, B.; Berninger, J. P.; Connors, K. A.; Chambliss, C. K.; Erickson, R. J.; Hoffman, A. D.; Brooks, B. W. Observed and modeled effects of $\mathrm{pH}$ on bioconcentration of diphenhydramine, a weakly basic pharmaceutical, in fathead minnows. Environ. Toxicol. Chem. 2015, 34 (6), 1425-35.

(16) Fu, W.; Franco, A.; Trapp, S. Methods for estimating the bioconcentration factor of ionizable organic chemicals. Environ. Toxicol. Chem. 2009, 28 (7), 1372-1379.

(17) Neuwoehner, J.; Escher, B. I. The pH-dependent toxicity of basic pharmaceuticals in the green algae Scenedesmus vacuolatus can be explained with a toxicokinetic ion-trapping model. Aquat. Toxicol. 2011, 101 (1), 266-275.

(18) OECD. Test No. 106: Adsorption-Desorption Using a Batch Equilibrium Method; OECD Publishing, 2000.

(19) USEPA. Methods for Acute Toxicity Testing with Fish, Macroinvertebrates and Amphibians; EPA-6601/3-75-009; National Technical Information Service: Springfield, VA, 1975.

(20) Carter, L. J.; Ashauer, R.; Ryan, J. J.; Boxall, A. B. A. Minimised Bioconcentration Tests: A Useful Tool for Assessing Chemical Uptake into Terrestrial and Aquatic Invertebrates? Environ. Sci. Technol. 2014, 48 (22), 13497-13503.

(21) Karlsson, M. V.; Marshall, S.; Gouin, T.; Boxall, A. B. A. Routes of uptake of diclofenac, fluoxetine, and triclosan into sedimentdwelling worms. Environ. Toxicol. Chem. 2016, 35 (4), 836-842.

(22) Avnimelech, Y.; Ritvo, G.; Meijer, L. E.; Kochba, M. Water content, organic carbon and dry bulk density in flooded sediments. Aquacultural Engineering 2001, 25 (1), 25-33.

(23) Erickson, R. J.; McKim, J. M.; Lien, G. J.; Hoffman, A. D.; Batterman, S. L. Uptake and elimination of ionizable organic chemicals at fish gills: II. Observed and predicted effects of $\mathrm{pH}$, alkalinity, and chemical properties. Environ. Toxicol. Chem. 2006, 25 (6), 1522-1532.

(24) Mayer, P.; Fernqvist, M. M.; Christensen, P. S.; Karlson, U.; Trapp, S. Enhanced Diffusion of Polycyclic Aromatic Hydrocarbons in Artificial and Natural Aqueous Solutions. Environ. Sci. Technol. 2007, 41 (17), 6148-6155.

(25) Karlsson, M. Uptake of Pharmaceuticals and Personal Care Products from Sediments into Aquatic Organisms, PhD Thesis, University of York, York, UK, 2013.

(26) Boxall, A. B. A.; Rudd, M. A.; Brooks, B. W.; Caldwell, D. J.; Choi, K.; Hickmann, S.; Innes, E.; Ostapyk, K.; Staveley, J. P.; Verslycke, T.; Ankley, G. T.; Beazley, K. F.; Belanger, S. E.; Berninger, J. P.; Carriquiriborde, P.; Coors, A.; DeLeo, P. C.; Dyer, S. D.; Ericson, J. F.; Gagne, F.; Giesy, J. P.; Gouin, T.; Hallstrom, L.; Karlsson, M. V.; Larsson, D. G. J.; Lazorchak, J. M.; Mastrocco, F.; McLaughlin, A.; McMaster, M. E.; Meyerhoff, R. D.; Moore, R.; Parrott, J. L.; Snape, J. R.; Murray-Smith, R.; Servos, M. R.; Sibley, P. K.; Straub, J. O.; Szabo, N. D.; Topp, E.; Tetreault, G. R.; Trudeau, V. L.; Van Der Kraak, G. Pharmaceuticals and Personal Care Products in the Environment: What Are the Big Questions? Environ. Health Perspect. 2012, 120 (9), 1221-1229. 